\title{
Monitoring and control system for logistics protection and transportation of urban solid waste based on big data
}

\author{
Yi H. ${ }^{1,2}$ and Ma H. ${ }^{1 *}$ \\ ${ }^{1}$ School of Economics and Management, Nanjing University of Aeronautics and Astronautics, Nanjing 210000, China \\ 2Department of Public Basic Course, Nanjing Institute of Industry Technology, Nanjing 210000, China \\ Received: 06/07/2020, Accepted: 04/08/2020, Available online: 21/10/2020 \\ *to whom all correspondence should be addressed: e-mail: mheng123@163.com \\ https://doi.org/10.30955/gnj.003414
}

\section{Graphical abstract}

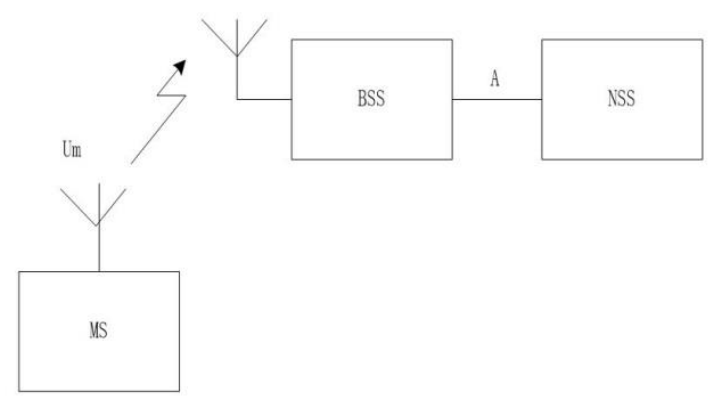

\begin{abstract}
Aiming at the problems existing in the traditional monitoring system for logistics protection and transportation of solid waste, the optimization design of logistics protection and transportation monitoring system is realized by using big data analysis technology from two aspects of hardware and software. In terms of hardware, the basic structure of the system server, internal components and connection circuit are modified, and the on-board weighing device is installed on the logistics transport vehicle. On the basis of the completion of hardware system installation, the interface of the system is designed and the database is built. The monitoring function of the system is realized through linking communication links, locating vehicle transportation location, real-time monitoring of transportation process, automatic weighing and abnormal alarm of logistics protection, so as to complete the optimization design of the software system. The experimental results show that compared with the traditional system, the response speed of the designed monitoring system for logistics protection and transportation increases by $67.6 \%$.
\end{abstract}

Keywords: Big data, urban solid waste, logistics protection, transportation monitoring system.

\section{Introduction}

City is a spatial and regional system of intensive population, economy, science and culture based on space and environment utilization, characterized by gathering economic benefits and aimed at the development of human society. It is the organic unity of economic entities, political entities, scientific and cultural entities and natural entities, and the political, economic and cultural center of modern society. Urban living environment is the basic condition to ensure urban economic development and people's life, and also the material basis for the normal functioning of the city. However, environmental problems have become the focus of contemporary society, and people's urban living environment is also under increasing threat (Aparcana, 2017; Suhaili and Samsudin, 2018). Among them, urban solid waste is a serious problem. The harmful components produced in the process of collection, transportation and treatment of urban solid waste will pollute the atmosphere, soil, water, etc. It is seriously affecting the quality of urban environment, threatening people's health and becoming a major public hazard. Solid waste of urban life refers to solid and semi-solid waste produced by human beings in production, consumption, life and other activities, mainly including solid particles, garbage, sludge, waste products, damaged utensils, defective products, animal corpses, spoiled food, human and animal excrement, etc. In some countries, high concentration liquids such as waste alkali, waste oil and waste organic solvents are also classified as solid wastes. However, in actual social life, solid waste in urban life is a mixture of many substances. Its composition is mainly affected by climatic conditions, urban development scale, residents' living habits, fuel structure and living standards.

In order to alleviate the negative impact of solid waste on urban environment, it is necessary to transport solid waste to a unified waste treatment plant, through classification, recovery, reuse and other steps to achieve the treatment of solid waste, which requires the use of fixed means of transport to transfer urban fixed waste to a designated location by means of logistics. However, in the process of transmission, there will be such problems as waste loss, so it is necessary to add protective functions to build transport monitoring system. According to the theory of logistics system, the collection and transportation system of urban solid waste is actually a kind of logistics system, that is, the logistics system of urban solid waste. The logistics system 
of urban solid waste is to collect, classify, pack and transport the goods which lose their original use value in the daily life of the city according to the actual needs, and then send them to the special treatment places separately (Ayaz and Dhali, 2020; Chaerul and Mulananda, 2018). From the point of view of system elements, the logistics system of urban solid waste consists of operators, workshops, working equipment, transport vehicles, management rules and regulations system, and from the process point of view, it consists of three small systems: solid waste collection, transit transportation, treatment and disposal. Because the characteristics of solid waste collection, transportation and disposal systems are quite different, they are generally studied separately. Due to the difference of domestic and foreign actual situation, there are great differences between the reserved protection and transmission monitoring system of urban solid waste in China and that in Western countries. The widely used systems include GPS-based monitoring system for logistics protection and transportation of urban solid waste, life cycle-based monitoring system for logistics protection and transportation of urban solid waste and Internet of Things-based monitoring system for logistics protection and transportation of urban solid waste (Dai et al., 2017; Rijal and Deykota, 2020). However, after a long period of application, it is found that there are some problems in the performance and function of the traditional monitoring system for logistics protection and transportation of urban solid waste, so the concept of big data is introduced. Big data refers to the massive, high growth rate and diversified information assets that need new processing mode to have stronger decision-making power, insight and process optimization ability. The concept of big data can be applied to the monitoring system for logistics protection and transportation, which can comprehensively make statistics and process the massive data generated by the monitoring system, thus improving the function execution rate and operation performance of the monitoring system.

\section{Design of hardware system for logistics protection and transportation monitoring of urban solid waste}

After analysis and design, the hardware system of urban solid waste logistics protection and transportation monitoring can be divided into two parts: monitoring center and vehicle terminal. The specific hardware system structure is shown in Figure 1.

In order to solve the problems existing in the traditional monitoring system, it is necessary to modify the structure of some components in the hardware system to improve the function of the monitoring system.

\subsection{System server}

The server in the monitoring system consists of three parts: Web server, DB server and location server. The Web server provides the function of Internet access for the system. By inputting the bill number or goods number of solid waste through the network client provided on the network, the goods on the way can be known and ready for delivery in advance. DB server is the core of the whole transportation enterprise operation, which is used for the storage and operation of the database, including vehicle information database, driver information database, freight order database, etc. The central dispatcher can call the information at any time (Elsaid and Aghezzaf, 2017; Humaira and Saima, 2018). The location server can receive the location information of the logistics vehicle sent by the vehicle and decode the location information, so that the location of the vehicle can be displayed on the electronic map, and the vehicle transportation route can be determined by the route optimization module according to the location information of the vehicle.

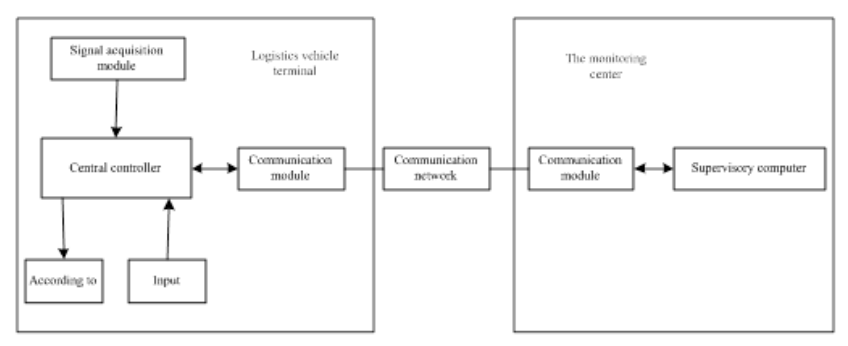

(a) Monitoring centre

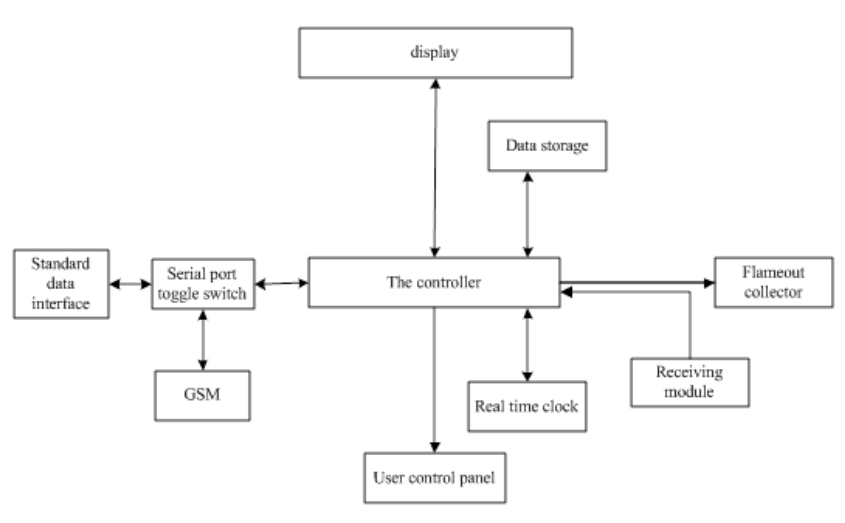

(b) On-board terminals

Figure 1. Structural diagram of hardware system for logistics protection and transportation monitoring

\subsection{Component selection and refitting}

\subsection{1. $M C U$}

MCU is a micro-control unit, which can reduce the frequency and specifications of CPU appropriately, and integrate peripheral interfaces such as memory, counter, USB, A/D conversion, UART, PLC, DMA, and even LCD driver circuits on a single chip to form a chip-level computer, which can control different combinations for different applications. MCU has two more suitable choices, 89C51 MCU and MSP430F149 MCU with low power consumption. The MCU of MsP430F149 is selected in the designed monitoring hardware system, and the 8-unit microcontroller on the market is converted into 16-bit components, which are converted into a streamlined instruction set structure to ensure that the component has rich addressing modes, concise 27 core instructions and a large number of analog instructions (Feo et al., 2017). In addition, $8 \mathrm{M}$ crystal oscillator is also needed to be connected to a single MCU component as XT2CLK. The 
software controls the operation of the program in the device. In addition, in order to prevent the damage of $\mathrm{MCU}$ during the development process from affecting the progress, the MCU is welded on a small board separately to facilitate replacement.

\subsubsection{GSM}

GSM refers to the global mobile communication components. The modified structure of the components is shown in Figure 2.

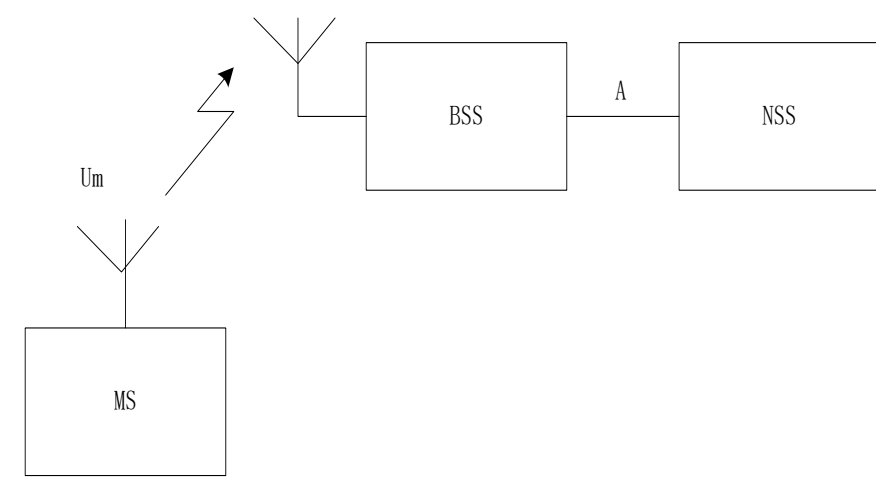

Figure 2. Refitting results of GSM communication components

The communication system is responsible for the data transmission between the positioning terminal and the monitoring center system, including the transmission of vehicle position information, status information, task information and control instructions of the monitoring center. The vehicle terminal has built-in GSM module and mobile communication card slot, through which the remote data interaction between vehicle logistics information and monitoring center can be realized.

\subsubsection{STM}

STM component of STM32 is selected as the core chip of the central control module of the vehicle terminal. Its internal part includes SDRAM and SIM928A program storage. DRAM memory is used for program operation and temporary data caching, and STM32 external EEPROM memory is used for storing important information such as measurement results (Fernándezgonzález et al., 2017; Sufiyan et al., 2018). Its USART serial interface is used to connect vehicle positioning module and wireless data transmission module, FMSC is used to connect display module, and DMA controller is used to realize the communication of each module. Its I/O interface is used to connect

the key module and the radio frequency front-end of the vehicle positioning module, and to control the corresponding module to achieve the corresponding module function.

\subsection{Vehicle weighing device}

A force sensor used in weighing sensors and weighing apparatus. The principle of resistance strain type weighing sensor is that it can convert the gravity acting on the measured object into a measurable output signal in a certain proportion. The traditional weighing sensor is refitted according to the form of vehicle, leading out multiple pins and installed in logistics vehicles. The pin setting and connection of the vehicle weighing device are shown in Table 1.

Table 1. Pin setting of vehicle weighing device

\begin{tabular}{cccccc}
\hline Pin & Name & Connectivity & Pin & Name & Connectivity \\
\hline 1 & VANT & Antenna power input & 11 & TXA & Main serial output \\
\hline 2 & PWRIN & Main power input & 12 & RXA & Main serial input \\
\hline 3 & VBATT & Backup battery & 13 & GND & Grounding \\
\hline 4 & PWRIN & Main power input & 14 & TXB & Main serial output \\
\hline 5 & RESET & Reset & 15 & RXB & Main serial input \\
\hline 6 & - & Keep & 16 & GND & Grounding \\
\hline 7 & - & Keep & 17 & GND & Grounding \\
\hline 8 & BOOT & Software upgrade interface & 18 & GND & Grounding \\
\hline 9 & - & Keep & 19 & PPS & IPPS time scale output \\
\hline 10 & GND & Grounding & 20 & GPSFIX & Work id
\end{tabular}

Table 2. Table of logistics vehicle information

\begin{tabular}{ccccc}
\hline The field names & The field type & Field size & A primary key (Y/N) & A foreign key (Y/N) \\
\hline Vehicle ID & Digital & Single precision type & $\mathrm{Y}$ & $\mathrm{N}$ \\
\hline The vehicle number & Text & 10 & $\mathrm{~N}$ & $\mathrm{~N}$ \\
\hline The driver's ID & Digital & Single precision type & $\mathrm{N}$ & $\mathrm{N}$ \\
\hline Date of annual examination of vehicle & Digital & Single precision type & $\mathrm{N}$ & $\mathrm{N}$ \\
\hline Vehicle equipment number & Text & 10 & $\mathrm{~N}$ & $\mathrm{~N}$ \\
\hline Card number of vehicle equipment & Text & 10 & $\mathrm{~N}$ & $\mathrm{~N}$ \\
\hline Color of logistics vehicles & Text & 4 & $\mathrm{~N}$ & $\mathrm{~N}$ \\
\hline Vehicle brand & Text & 20 & $\mathrm{~N}$ & $\mathrm{~N}$ \\
\hline Maintenance record & Text & 200 & $\mathrm{~N}$ & $\mathrm{~N}$ \\
\hline
\end{tabular}


Table 3. Table of monitoring information

\begin{tabular}{ccc}
\hline The field names & The field type & Field size \\
\hline Car station ID & Digital & Single precision type \\
\hline Date & Text & 20 \\
\hline Longitude & Text & 20 \\
\hline Latitude & Text & 20 \\
\hline Location & Text & 100 \\
\hline Speed & Text & 20 \\
\hline Traffic state & Text & 50 \\
\hline
\end{tabular}

\subsection{Circuit design}

The circuit in the hardware system for logistics protection and transportation monitoring of urban solid waste has two main functions: one is to connect the components and equipment in the hardware system to realize the interaction between signals; the other is to continuously supply power for each hardware component and equipment (Gnoni et al., 2017; Sarwar et al., 2019). In the hardware system of logistics protection and transportation monitoring, the circuit is refitted and designed, including component interface circuit, power supply circuit and receiving module circuit. The power supply circuit uses 12 $\mathrm{V}$ on-board power supply. Because the power supply of automobile battery is not stable and there is a problem of level conversion, it is necessary to convert the voltage of 12 $\mathrm{V}$ to the required voltage by using the step-down voltage regulator LM2596.

\section{Design of monitoring software system for logistics protection and transportation of urban solid waste}

Software system is the core of the whole remote monitoring system, which is responsible for the data exchange, operation, storage, display and other processing functions, including monitoring center system, geographic information system and database (Kamal and Youlla, 2018). On the basis of the theory of logistics monitoring system construction, the system construction is carried out on the basis of analyzing the characteristics, objectives and composition of urban solid waste logistics system. Through the prediction of logistics volume and waste composition, the nature and flow of the fluid in the logistics system are determined, so as to determine the construction scale and system construction objectives of the monitoring system.

\subsection{Design of system interface}

The software system for logistics protection and transportation monitoring of urban solid waste includes two parts: basic information management part and navigation part. Basic information management mainly refers to the management of user accounts and passwords. The operation safety of transportation monitoring system can be guaranteed by setting up the basic information management part. In addition, the basic information management of the transport monitoring software system can grant different privileges according to different users, so that different program commands can be executed. The navigation part is mainly divided into inquiry function navigation and monitoring function navigation. Logistics protection and transportation monitoring and inquiry function module can be divided into playback of logistics history track, inquiry of logistics waybill and classification inquiry of urban solid waste goods (Jamil et al., 2018; Liu et al., 2017). Through the design of interface of monitoring system for logistics protection and transportation of urban solid waste, it not only can enhance the visual beauty of the system, but also can simplify the operation steps of the system.

\subsection{Database design}

\subsubsection{Creating database table of the system}

Through demand analysis, we can draw a conclusion that logistics monitoring system includes vehicles, logistics providers, terminal equipment and other entities. According to the analysis of these entities, several database tables have been established as: vehicle basic information table, logistics providers basic information table, vehicle grouping information table, terminal equipment table, logistics positioning information table, sending information table, alarm information table and vehicle alarm setting table. Some of the data tables created are shown in Table 2.

Similarly, the monitoring information table established in the database is shown in Table 3.

\subsubsection{Database storage and access}

The difficulty of database storage and access lies in the storage and access of spatial data and attribute data in system spatial database (Liu et al., 2017). The spatial data and attribute data in the monitoring system database are stored and managed separately, and the connection of the two types of data is realized by indexing the related data of spatial data and attribute data (Moraci et al., 2018). Users can access spatial data and attribute data simultaneously, and also can access spatial data and attribute data separately. Because the logistics protection and transportation of urban solid waste will be affected by the development of the city, which will produce some invalid data, it is necessary to access the established database to update the database by adding, modifying, deleting and searching.

\subsection{Design of monitoring function module in the system}

Based on the logistics protection transport process of urban solid waste, the system monitoring function module is designed. Generally, the logistics transport process of urban solid waste is divided into four steps: waste collection, transportation, resource utilization and final treatment. The concrete realization process of the logistics 
protection transport monitoring function is shown in Figure 3.

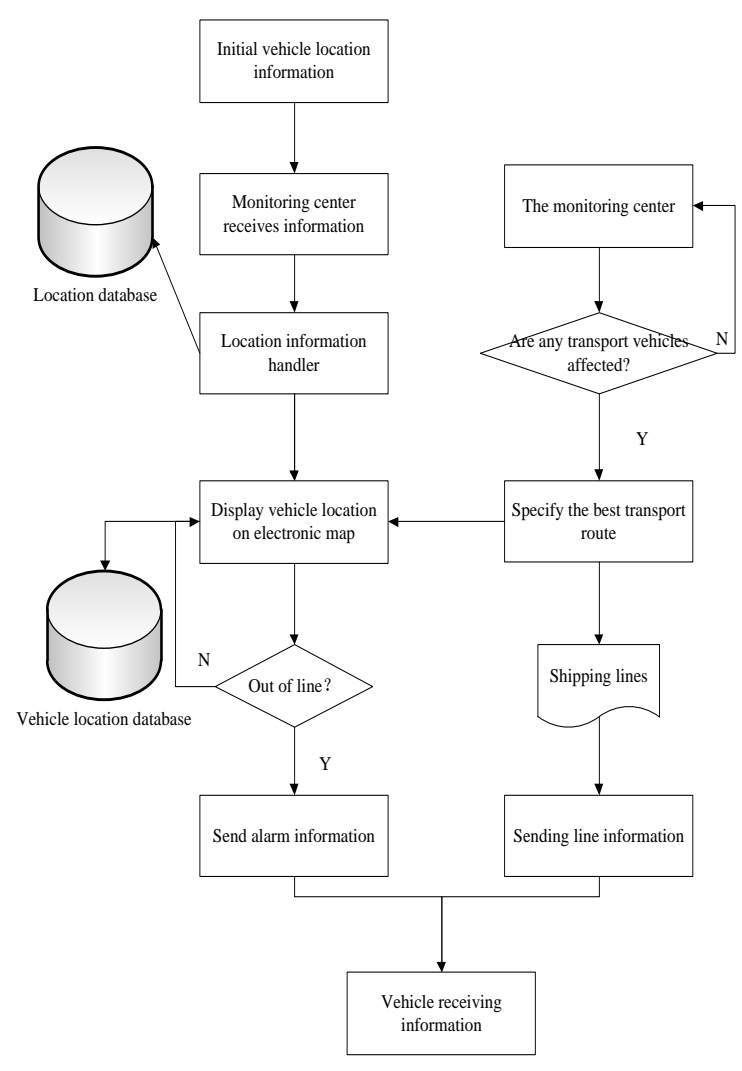

Figure 3. The realization flow chart of system monitoring function

\subsubsection{Connecting the communication link of monitoring center}

According to the analysis of the overall framework of the system, the subsystem of the monitoring center should have functions of communication, visual monitoring and dispatching, database management and decision support. These modules complete the functions of data processing and storage, vehicle monitoring and dispatching, alarm processing, system maintenance and distribution information release (Moretto et al., 2019). By configuring the monitoring computer of the monitoring center and the hardware equipment of the logistics transportation vehicle, the signals and data generated by the logistics transportation vehicle can be transmitted to the monitoring center at the fastest speed. The monitoring center sends control instructions through processing and analyzing the received data information, thus realizing the monitoring of the logistics protection transportation of urban solid waste.

\subsubsection{Locating the transportation location of logistics vehicle}

The real-time vehicle monitoring system uses timer to read the latest location record of the monitorable vehicle from the database. The location data is displayed on the electronic map. All monitorable vehicles will be displayed on the map. The license plate number of the monitorable vehicle will be bound to the tree control. When the user clicks on the vehicle on the tree control or the selection button on the map and clicks on a vehicle, the vehicle will be displayed in the center, and the vehicle's waybill information, vehicle location information and driver information can be viewed. During the monitoring process, the real-time vehicle location information in the database is read every two minutes to obtain the latest vehicle location information (Nannoni et al., 2017; Siew et al., 2019). The real-time positioning process of logistics vehicle transportation location is shown in Figure 4.

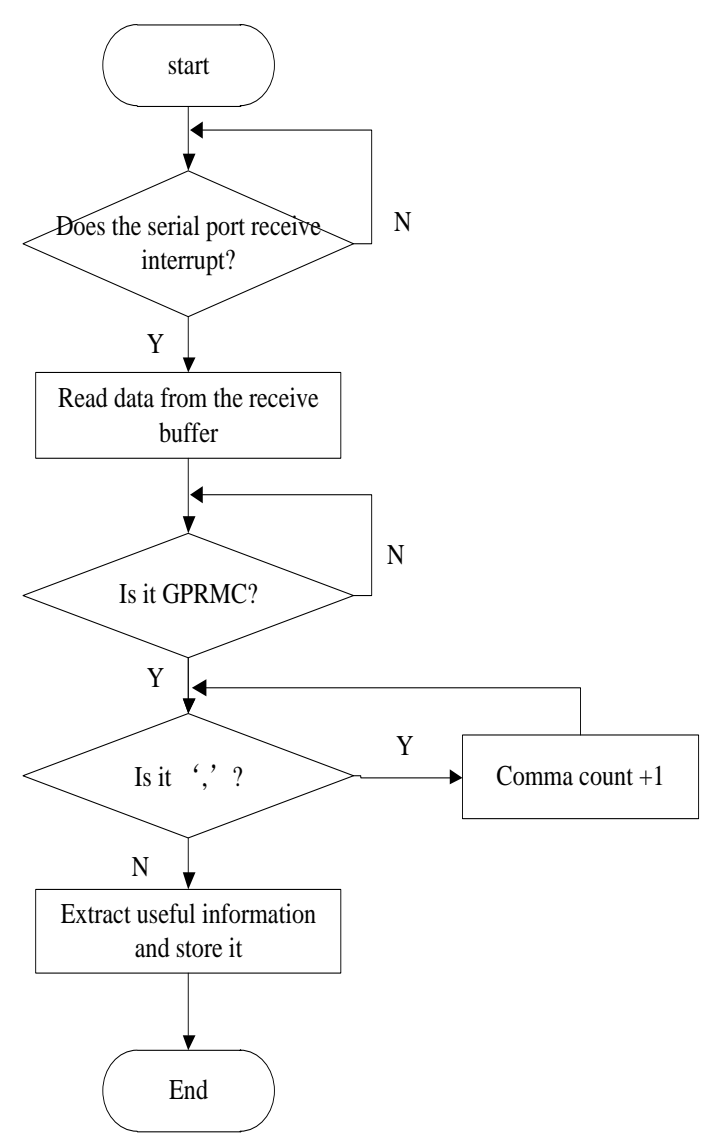

Figure 4. Flow chart of receiving and extracting location data of logistics vehicles

For vehicles on the road, the trajectory route of vehicles will be formed, which will be displayed on the map with blue lines, and at the same time, the specific points of the trajectory will be displayed in the table below the map. Clicking on any record in the table can also show the detailed information of the location (Rastyapina and Kalachnikova, 2018). For the vehicle trajectory formed on the map, you can right-click on the route and click "route offset correction" to achieve route correction. After correction, a red line will be formed, parallel to the previous blue line.

\subsubsection{Real-time monitoring of the transport process of urban solid waste}

Figure 5 shows the basic transport process of urban solid waste.

According to the operation mode in the figure, firstly, the solid waste is mixed and collected, and the suitable transportation mode and disposal method are selected according to the distance between the producing place and 
the transfer station and the disposal site, as well as the characteristics and quantity of the solid waste. Secondly, the solid waste is transformed into energy by chemical or biological conversion, releasing the energy contained in the solid waste and utilizing it. Finally, through composting, incineration, landfill and other operations to achieve the final treatment of solid waste (Santos et al., 2017). Through the signal transmission of sensors, the monitoring center can roughly judge the current logistics transportation stage of urban solid waste.

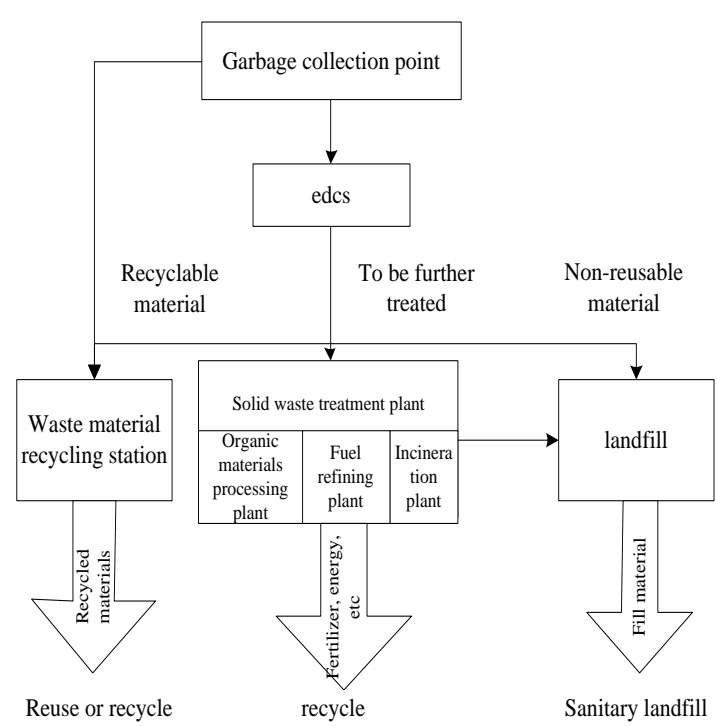

Figure 5. Flow chart of urban solid waste disposal logistics

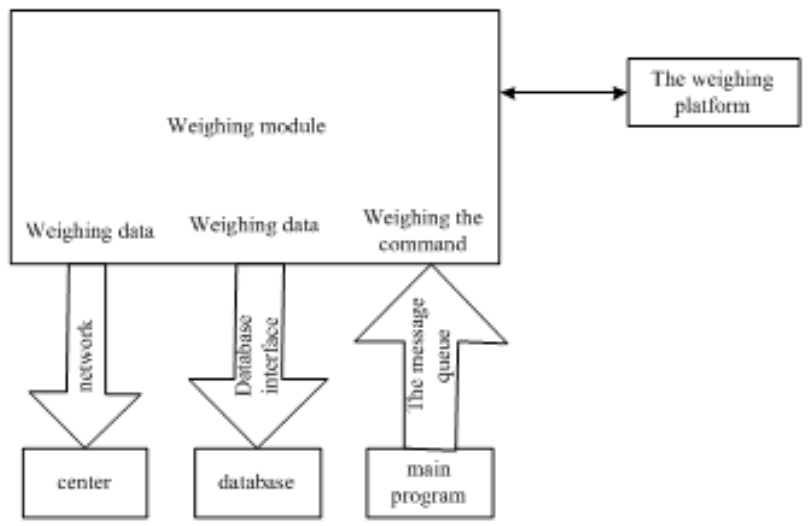

Figure 6. Block diagram of automatic weighing

\subsubsection{Automatic measurement of waste logistics flow}

The vehicle weighing sensor in hardware system is used to monitor the weight of solid waste in real time. In each transport process, the data transmitted by weighing equipment can be used to determine whether there is loss of goods in the transport process. The block diagram of automatic weighing of solid waste logistics flow is shown in Figure 6.

In addition, due to the limitation of vehicle transport capacity and processing capacity, it is necessary to set capacity constraints as one of the monitoring parameters. The expression of logistics vehicle transport capacity constraints is as follows:

$$
\min B_{k} \leq \sum_{i=1}^{l} x_{i k} \leq \max B_{k}, k=1,2, \cdots, K
$$

where, $B_{k}$ is the transport capacity of logistics vehicles, and $x_{i k}$ is the measurement result of the output of the automatic weighing measurement program.

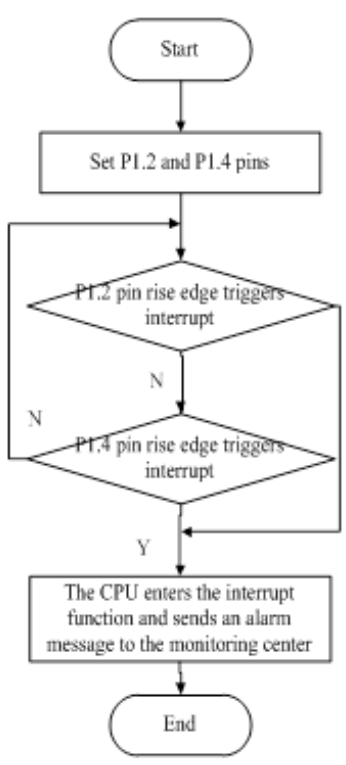

(a) flow chart of emergency alarm procedures

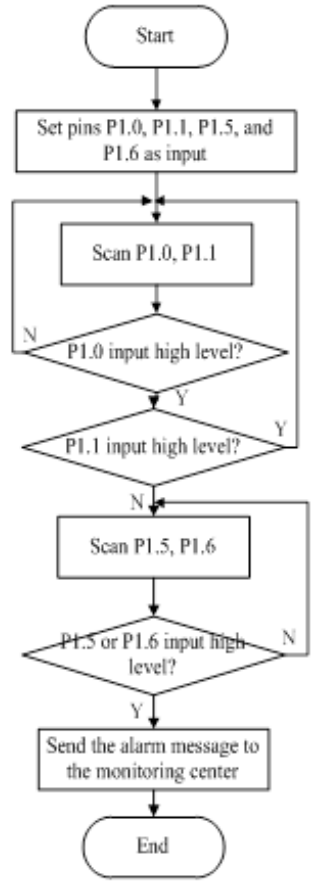

(b) flow chart of burglar alarm procedure
Figure 7. Flow chart of abnormal alarm program

\subsubsection{Logistics protection abnormal alarm}

Logistics protection abnormal alarm is divided into three situations: emergency alarm, burglar alarm and status alarm. The realization process of burglar alarm and emergency alarm is shown in Figure 7.

In the emergency alarm execution procedure, when the driver decides that someone wants to hijack, he can press the emergency alarm button, and the monitoring center receives the alarm signal from the vehicle terminal. The alarmed vehicle displays the alarm status and location in a striking way on the map, and raises the monitoring level of the alarm target. The monitoring center immediately gives an alarm, and according to the alarm situation and police force distribution, conducts command dispatch and police situation processing with short message. The anti-theft anomaly can be divided into two cases, one is the theft of goods and the other is the loss of goods in the process of logistics transportation. When the terminal starts, it will output a high level when the human body moves. When the vibration sensor vibrates, its output pin will output a high level (Wei and Pivato, 2017). The output pin of the test result is connected with the P1.5 pin of the single chip computer. The output pin of the vibration sensor is connected with the P1.6 of the single chip computer. Usually or when receiving the withdrawal order, the CPU will stop scanning the P1.5 and P1.6 pin input. Once receiving the deployment order, the $\mathrm{CPU}$ will start scanning 
the P1.5 and P1.6 pin input. If any input level between the two pins is scanned, it will send an alarm message like the monitoring center. The state alarm is from the upper limit of the downward speed of the monitoring center system and the regional boundary coordinates to the on-board subsystem, which is saved by the on-board terminal (Wang et al., 2018; Xiong et al., 2019). In the course of driving, if the actual driving speed exceeds the upper limit value of speed, the action of reporting the alarm information of overspeed to the monitoring center shall be executed immediately. If the area specified by the monitoring center is driven out, the action of reporting the alarm information of overspeed area to the monitoring center shall be executed immediately. The monitoring center system records the alarm information and immediately notifies the staff on duty with voice prompt and text prompt information, and provides timely and complete alarm information and processing flow for the staff on duty with the location information on the electronic map.

\section{System test}

The hardware environment of the system's operating

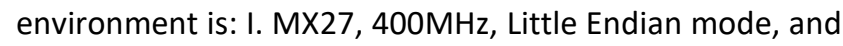
the software environment is: Linux 2.6.19. System performance testing mainly tests the running time and processing capacity of the system. The corresponding experimental environment is shown in Figure 8.

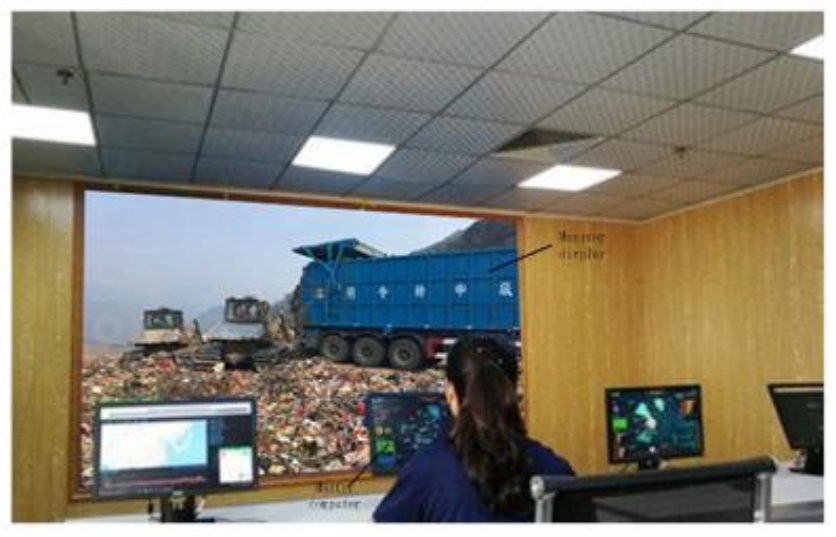

Figure 8. Test environment of the system

In this system test experiment, the traditional transport monitoring system is set up as a comparative system, which emphasizes the performance of the monitoring system for logistics protection and transportation of urban solid waste based on big data (Yu et al., 2019). The alarm function and logistics position control function of the monitoring system are tested respectively. Firstly, the part of urban solid waste is lost artificially, and the alarm time of the two systems is counted. Then, the speed and route of transport vehicles for logistics protection are controlled. The operation results of the two monitoring systems are input into the third-party data statistics and analysis software, and the system test results are compared as shown in Figure 9.

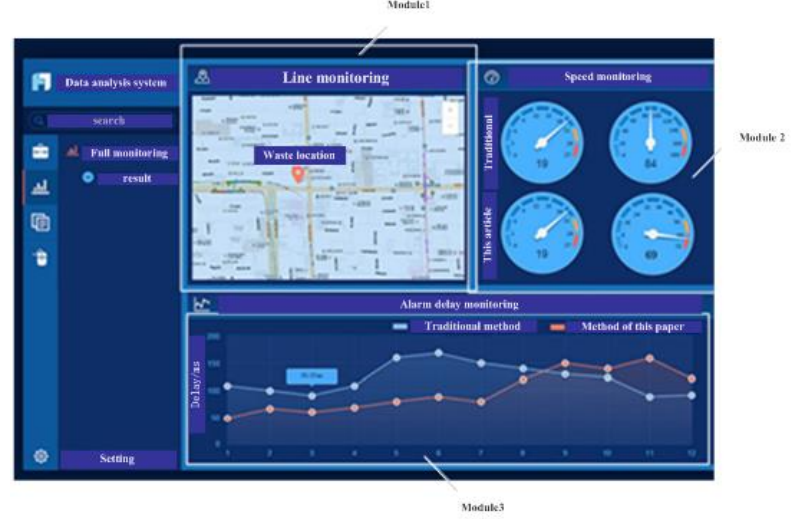

Figure 9. Comparison results of systematic test

In the figure, module 1 is used to show the transportation routes of monitoring and control of the two systems. Module 2 shows the running speed of logistics vehicles corresponding to the system before and after control, and module 3 is the alarm delay. Through statistics and calculation, the speed of monitoring system for logistics protection and transportation of urban solid waste based on big data is increased to $84 \mathrm{~km} / \mathrm{h}$ in 2 minutes, and the speed of the corresponding transport vehicle in traditional system is $77 \mathrm{~km} / \mathrm{h}$. The transportation speed is set as 85 $\mathrm{km} / \mathrm{h}$, so the control error of the design monitoring system is $1 \mathrm{~km} / \mathrm{h}$, and that of the traditional system is $8 \mathrm{~km} / \mathrm{h}$. In terms of alarm response time, the average response of traditional monitoring system is $150 \mathrm{~ms}$, while the average response of monitoring system for logistics protection and transportation of urban solid waste based on big data is 50 $\mathrm{ms}$, which is $67.6 \%$ faster than that of traditional monitoring system.

\section{Conclusion}

The ecological regulation and control of urban solid waste is not only a management work, but also a systematic project which studies the environment, economy, material, industry and sociology in an all-round way. Through the design and application of the monitoring system for logistics protection and transportation of urban solid waste based on big data, the problems existing in the traditional monitoring system are effectively solved, the function realization ability and response time of the monitoring system are improved, and the living environment of the city is indirectly improved. However, the current system is not perfect enough and needs further modification and expansion. In the next step, the system can be improved from many aspects such as solid waste identification.

\section{References}

Aparcana S. (2017), Approaches to formalization of the informal waste sector into urban solid waste management systems in low- and middle-income countries: Review of Barriers and Success factors, Waste Management, 61, 593-607.

Ayaz S. and Dhali M.K. (2020), Longitudinal profiles and geomorphic indices analysis on tectonic evidence of fluvial form, process and landform deformation of Eastern Himalayan Rivers, India, Geology, Ecology, and Landscapes, 4, $11-22$ 
Chaerul M. and Mulananda A. M. (2018), Minimization of urban solid waste transportation route in West Jakarta using Tabu Search method, IOP Conference Series Earth and Environmental Science, 148, 012026.

Dai F., Dai W. and School M. (2017), Analysis of an evolutionary game under urban solid waste incineration power generation based on system dynamics, Industrial Engineering Journal, 11, 62-65.

Elsaid S. and Aghezzaf E.H. (2017), A progress indicator-based assessment guide for integrated urban solid-waste management systems, Journal of Material Cycles \& Waste Management, 13, 1-14.

Feo G.D., Ferrara C. and Finelli A., et al. (2017), Environmental and economic benefits of the recovery of materials in a urban solid waste management system, Environmental Technology, 22, $1-24$.

Fernándezgonzález J.M., Grindlay A.L., Serranobernardo F., et al. (2017), Economic and environmental review of Waste-toEnergy systems for urban solid waste management in medium and small urbanities, Waste Management, 67, 360-374.

Gnoni M.G., Lettera G. and Rollo A. (2017), A feasibility study of a RFID traceability system in urban solid waste management, International Journal of Information Technology \& Management, 12, 27-38.

Humaira G. and Saima N. (2018), Heavy Metal Uptake from Contaminated Water Using Carbon Nanotubes: A Review, Environmental Contaminants Reviews, 1, 04-08.

Jamil F., Arshad R. and Ali M.A. (2018), Design, Fabrication and Evaluation of Rotary Hot-Air Dryer for The Value Addition of Fruit Waste, Earth Sciences Pakistan, 2, 7-11.

Kamal M.A. and Youlla D. (2018), Urban solid waste transportation optimisation with vehicle routing approach: case study of Pontianak City, West Kalimantan, IOP Conference Series: Earth and Environmental Science, 131, 012057.

Liu G., Yan H., Liang D., et al. (2017), An emergy-LCA analysis of urban solid waste management, Resources Conservation \& Recycling, 17, 120-123.

Liu L., Kong S. Zhang Y., et al. (2017), Morphology, composition, and mixing state of primary particles from combustion sources - crop residue, wood, and solid waste. Science Reports, 7, 5047-5055.

Moraci N., Busana S., Cortellazzo G., et al. (2018), Design and construction of a compacted clay liner in cover system of a urban solid waste (MSW), landfill using nonstandard procedures, Canadian Geotechnical Journal, 55, cgj-20170371.

Moretto G., Ardolino F., Piasentin A., et al. (2019), Integrated anaerobic codigestion system for the organic fraction of urban solid waste and sewage sludge treatment: an Italian case study, Journal of Chemical Technology \& Biotechnology, 35, 121-134.

Nannoni F., Mazzeo R., Santolini R., et al. (2017), Multi-matrix environmental monitoring to assess heavy element distribution around a urban solid waste landfill in Italy, International Journal of Environmental Science \& Technology, 14, 1-12.

Rastyapina O.A. and Kalachnikova E. V. (2018), Comprehensive approach to solid waste disposal from urbanized territories, IOP Conference Series Materials Science and Engineering, 451, 012132.
Rijal S. and Devkota Y. (2020), A Review On Various Management Method of Rice Blast Disease, Malaysian Journal of Sustainable Agriculture, 4, 29-33.

Santos S.M., Silva M.M., Melo R.M., et al. (2017), Multi-criteria analysis for urban solid waste management in a Brazilian metropolitan area, Environmental Monitoring \& Assessment, 189, 561.

Sarwar M.T., Hui Z.H., Xin Y.J., Jiang S.W., Yong T., Jie L.B. and Song T.S. (2019), Mitigation Techniques To Overcome Water Scarcity Issues, Water Conservation and Management, 3, 3031.

Siew Z.B., Chin C.M.M. and Sakundarini N. (2019), Designing A Guideline for Green Roof System in Malaysia, Journal Clean Was, 3, 05-10.

Sufiyan I., Zakariya R., Yacoob R., Idris M.S. and Nasir M.I. (2018), SWAT Subbasins Parameters and Flood Risk Simulations Using 3d In Terengganu Watershed, Earth Sciences Malaysia, 2, 1015.

Suhaili M.Z. and Samsudin M.D.M. (2018), Utilization of Wastewater for Corrosion Prevention of Carbon Steel Pipe Using Single Chamber Microbial Fuel Cells, Environment \& Ecosystem Science, 2, 47-52.

Wang L., Zheng K., et al. (2018), Affinity propagation clustering algorithm based on large-scale data-set, International Journal of Computers and Applications, 40, 1-6.

Wei P. and Pivato A. (2017), Sustainable management of digestate from the organic fraction of urban solid waste and food waste under the concepts of back to earth alternatives and circular economy, Waste \& Biomass Valorization, 25, 1-17.

Xiong Z., Wu Y., et al. (2019), Color image chaos encryption algorithm combining CRC and nine palace map, Multimedia Tools and Applications, 78, 31035-31055.

Yu D., Zhu H., et al. (2019), Dynamic multi agent-based management and load frequency control of PV/Fuel cell/Wind turbine/CHP in autonomous microgrid system, Energy, 173, 554-568. 